\title{
An Update on Novel COVID-19 Pandemic; A Battle between Humans and Virus
}

\author{
Suneel Prajapati ${ }^{1}$, Mahima Sharma ${ }^{1}$, Arun Kumar ${ }^{1}$, Pankaj Gupta ${ }^{1}$, and Narasimha \\ Kumar G.V. ${ }^{2}$ \\ ${ }^{1}$ Dr. DP Rastogi Central Research Institute for Homeopathy \\ ${ }^{2}$ Dr. Anjali Chatterjee Regional Research Institute for Homeopathy
}

April 29, 2020

\begin{abstract}
In the $21^{\text {st }}$ century, human civilization, has witnessed three major epidemics caused by Coronaviruses namely severe acute respiratory syndrome coronavirus (SARS-CoV) in 2003, Middle East respiratory syndrome coronavirus (MERS-CoV) in 2012 and 2019-novel coronavirus (2019-nCoV) or coronavirus disease (COVID-19) in 2019. Among these, COVID-19 has greater transmission and mortality rate. $2019-\mathrm{nCoV}$ belongs to a large family of positive sense single-stranded RNA viruses ( + ssRNA) that can be isolated in different animal species. The most communal symptoms of COVID-19 include fever, cough, and shortness of breath during the incubation period (2-14 days) of infection. COVID-19 transmission is occurring from infected humans to close contact with one another through respiratory droplets, coughs, and sneezes of infected person. Moreover, the virus containing surfaces may also transmit the infection. Diagnosis is being carried out by collecting a nasopharyngeal swab or sputum specimen for detection of SARS-CoV-2 RNA by reverse-transcription polymerase chain reaction (RT-PCR). Rapid diagnosing methods are also under development which can diagnose COVID 19 in few minutes to hours. Currently, there is no specific cure or preventive therapeutics available. Hence, based upon limited in-vitro and anecdotal data, Chloroquine, or Hydroxychloroquine, Remdesivir, Lopinavir and Ritonavir are being employed in the management. Search for new specific anti-viral drugs from natural/synthetic origins is under full swing and many of them are currently used as chemotherapeutic drugs under clinical investigation. Yet, there is a strong need for development of vaccine, which may take several months to few years for the development.
\end{abstract}

\section{Introduction}

Epidemic outbreak of a viral disease is a curse for human civilization and represents a serious issue to public health. In last two decades, several viral diseases have been reported such as the Ebola, Swine flu, Bird $\mathrm{flu}$, Hanta virus, H1N1 influenza and severe acute respiratory syndrome coronavirus (SARS-CoV) ${ }^{1}$. Among all viral outbreaks, epidemic of SARS-CoV has been more severe and shown to have high transmission rate. SARS is a zoonotic disease caused by SARS-CoV ${ }^{2}$, first emerged in China in 2002 and later it was reported in other parts of the world in 2003 and affected 8,908 people with $9.6 \%$ fatality rate. Similarly to new COVID-19, the nosocomial transmission of SARS-CoV was related with travel history. The primary reservoir is also suspected through bats, although unproven and more intermediary source also suggested transmission via civet cats in the wet markets in Guangdong ${ }^{3}$. MERS (Middle East respiratory syndrome), a novel lethal zoonotic disease of humans caused by another member of corona virus family i.e. MERS-CoV. Humans are thought to acquire MERS-CoV infection through contact with camels or camel products with a fatality rate of $35 \%$ while nosocomial transmission is also a hallmark ${ }^{4}$. In late 2019 , the recent outbreak of a novel human coronavirus (beta-coronavirus) that is now termed as severe acute respiratory syndrome coronavirus 2 (SARS-CoV-2 or HCoV19 or COVID-19) has reported in Wuhan, China, which announced as 
a pandemic by World Health Organization (WHO) ${ }^{5}$. On December 2019, WHO office of China perceived 29 cases of pneumonia like disease in Wuhan, however they unable to identify the causative agent, and classified it as "pneumonia of unknown etiology." The Chinese Center for Disease Control and Prevention (CDC) had organized an intensive outbreak investigation program ${ }^{6}$ and now the etiology of this illness has attributed to a novel virus belonging to the coronavirus (CoV) family, COVID-19.

\subsection{Primary findings and scientific features of COVID-19:}

Corona viruses $(\mathrm{CoV})$ have become the major pathogens of emerging outbreaks of respiratory disease. They are a large family of single-stranded RNA viruses (+ssRNA) that can be isolated in different animal species ${ }^{7}$. For reasons yet to be explained, these viruses can cross species barriers and cause human illness ranging from common cold to more severe diseases such as MERS and SARS. The most common symptoms include fever, cough, and shortness of breath, while muscle pain, sputum production and sore throat are less common ${ }^{8,9}$. In January 2020, pathogen of several groups of patients with lower respiratory tract infection was isolated and identified as novel coronavirus (2019-nCoV) through unbiased sequencing and other scientific techniques 10. The reported genomic studies showed that identified 2019-nCoV have similarity with SARS-CoV which was found in bats. Furthermore, it suggested that angiotensin-converting enzyme II (ACE-2) is a possible target receptor for this novel virus to enter inside the cell ${ }^{11-14}$. The most affected organ by COVID-19 is lungs which have most abundant ACE2 receptor in the type II alveolar cells. . The virus uses a special surface glycoprotein, called "spike", to connect to ACE2 receptor and enters the host cell ${ }^{15}$. Incubation period of the COVID 19 is 2-14 days. However, a case with an incubation period of 19 days was observed in a JAMA study of 5 cases and published on Feb. $21^{16}$. In addition on Feb. 22, a case with an incubation period of 27 days has been reported by Hubei Province local government ${ }^{17}$. Hence, virus should be differentiated from the common cold by clinical presentations and available test parameters. There are some unique features for COVID-19 such as persistent antigenic changes and cause severe pneumonia and multi-organ failure which may leads also mortality ${ }^{18}$. Aim of this review is to provide the literature of early findings on the clinical manifestation, epidemiology, causes, transmission, clinical diagnosis, as well as prevention and control of COVID-19. This review can deliver evocative information to policy makers and governments in decision to make strategies for handling this pandemic at community, national, and international levels.

\subsection{Global COVID 19 Burdens and Mortality}

Globally, the incident rate of COVID-19 is increasing very rapidly. Total 2,285,210 positive corona cases with 155,124 deaths have been reported in 206 countries till April 20, 202019. Although, average rate of death per number of diagnosed cases is $4.1 \%$. Furthermore, it ranges from $0.2 \%$ to $15 \%$ depending on age and other health problems ${ }^{20}$. The mortality rate was reported $4.9 \%$ in Wuhan, $3.1 \%$ in Hubei Province, and $2.1 \%$ throughout the China ${ }^{21}$. After China, USA, Italy, Spain, France, Germany and Iran have emerged as epic centers of COVID 19 and transmitted to other countries with an alarming high rate (Fig-1). In USA 723,605 confirm positive cases and 34,203 death were reported followed by Spain 191,726 and Italy, 115,242 positive corona virus cases and 20,043 and 23,227 death have been found till April 20, 2020. The average of death rate in Italy seems to be very high in comparison to any other country ${ }^{22}$. 


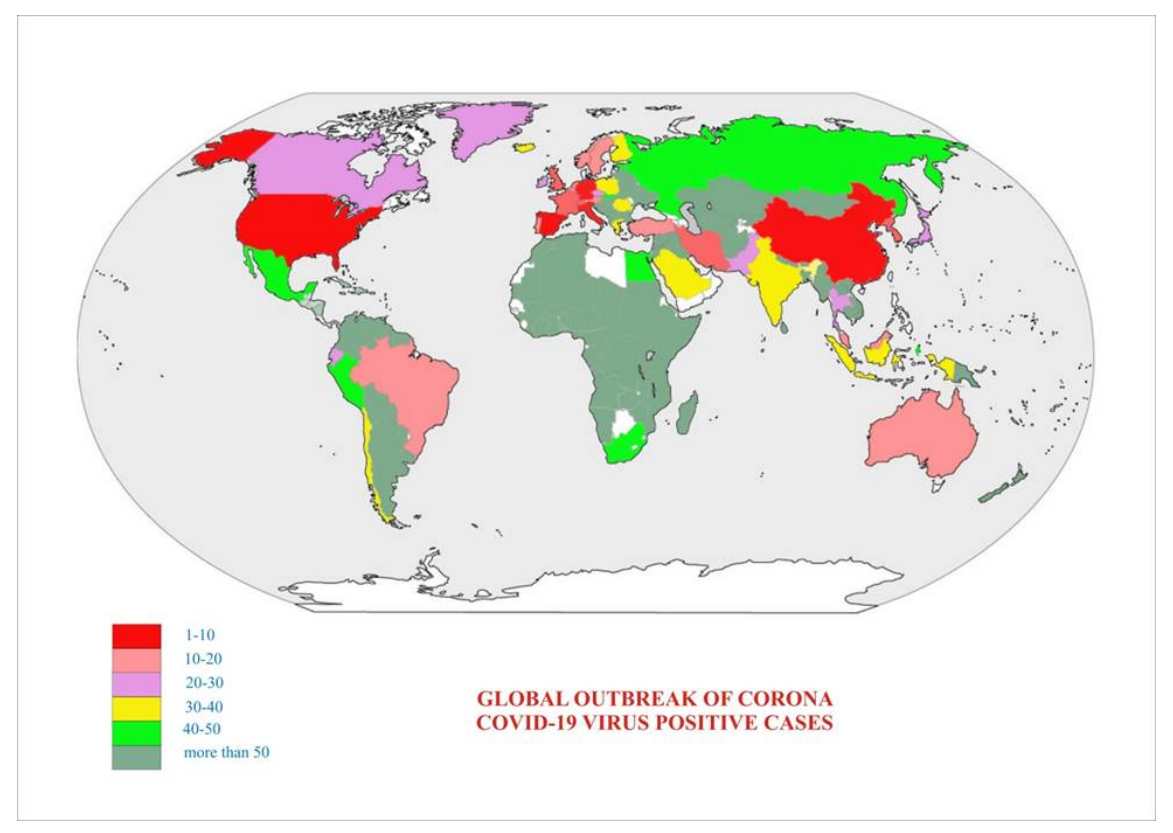

Figure: 1 Global burden of COVID-19 positive cases are indicated in legends in which 1-50 shows different level of severity in different regions of the world map.

\subsection{Etiology}

The etiology of illness is now attributed to a novel virus belonging to the coronavirus (CoV) family, COVID19. This new virus seems to be very contagious and spreading very rapidly with startling rate all around the globe ${ }^{23}$. Several known coronaviruses are circulating in animals and most of them have not yet infected humans. The SARS-CoV-2 is also known as $\beta$-coronavirus, which is enveloped non-segmented positive-sense ssRNA virus (subgenus sarbecovirus, Orthocoronavirinae subfamily) ${ }^{24}$. CoV are divided into four genera, including $\alpha, \beta, \gamma$ and $\delta-\mathrm{CoV}$ in which $\alpha$ - and $\beta-\mathrm{CoV}$ are associated to infect the mammals, while $\gamma$ - and $\delta$-CoV able to infect birds. Previously, six CoVs have been identified as human-susceptible virus with low pathogenicity and cause mild respiratory symptoms similar to common cold viz; $\alpha-\mathrm{CoVs}$, HCoV-229E,HCoVNL63, $\beta$-CoVs, HCoV-HKU1 and HCoV-OC43. The other two known SARS-CoV and MERS-CoV lead to severe and potentially fatal respiratory tract infections ${ }^{25}$. Genome sequence analysis revealed that SARSCoV-2 was $96.2 \%$ identical to bat CoV RaTG13, whereas it shares $79.5 \%$ identity to SARS-CoV. Based on virus genome sequencing and evolutionary analysis, bat has been suspected as natural host of SARSCoV-2 virus origin and might be transmitted from bats via unknown intermediate hosts to infect humans. SARS-CoV-2 use angiotensin-converting enzyme 2 (ACE2) as target receptor, the same as SARS-CoV ${ }^{26}$.

\subsection{Epidemiology:}

The COVID19 genomic analysis provides the clues about its origin. During an outbreak in China province a COVID19 genetic code may steadily mutate as it spreads through a population. The mutations are slight often just a single letter change in the code, like from AATC to ATTC. The mutations provide a time and geographical stamp of sorts. Acute respiratory tract infection first appeared in Wuhan, China, possibly related to a seafood market since 12 December 2019. Various ongoing research studies revealed that bat may be the potential source of SARS-CoV-2 ${ }^{27,28}$. However, there is no evidence so far that the origin of SARS-CoV-2 was from the seafood market. From its first appearance in china COVID19 has spread to more than two hundred other countries including Asia, Europe, North America, South America, Africa, and Oceania etc ${ }^{29}$. At present, COVID19 is spreading rapidly from human to human contact through air droplet transmission in all these regions ${ }^{30,31}$. COVID19 was designated as a public health emergency by the 
WHO and on 11 March 2020, declared as a pandemic ${ }^{32,33}$. Genomic epidemiology of hCoV-19 in Guangdong Province, China reported that the genome sequences from Guangdong are interspersed across the COVID-19 outbreak phylogeny. The Guangdong sequences substantially extend the known genetic diversity of hCoV-19 genomes from China ${ }^{34}$. Furthermore, sequencing of COVID19 study from other geographical reasons will very likely increase this diversity further.

\subsection{Transmission:}

COVID-19 is transmitted person-to-person via close contact with one another (within about 6 feet), through respiratory droplets produced from coughing or sneezeing of infected person. These droplets may land in the mouth, nose, and eyes of nearby people and possibly reach lungs by inhalation ${ }^{35}$. Asymptomatic carrier transmission has been reported for SARS-CoV-2 ${ }^{36}$; hence, anyone if found having close contact with infected persons should be quarantined for specified incubation period and then hospitalized on the basis of positive test (PCR) result only ${ }^{30}$. Although, the extent to which this occurs remains unknown, a large-scale serologic screening test may be able to provide a better sense of asymptomatic infections and inform epidemiologic analysis. Recently, Cai et al $2020^{37}$ have reported that indirect transmission of the causative virus occurred and suspected via resulting from virus contamination of common objects, virus aerosolization in a confined space, and spread from asymptomatic infected persons (Fig-2). According to U.S. National Academies of Science, COVID-19 may spread through the air in tiny particles that infected people exhale during normal breathing and speech. "Currently available research supports the possibility that SARS-CoV-2 could be spread via bio-aerosols generated directly by patients' exhalation ${ }^{38-40}$. Therefore, it can be said that SARSCoV-2 can survive outside the body for long time and spread rapidly via various fomites (e.g., elevator buttons or restroom taps, metro handrails, public transport, common hand wash facility and via currency) or virus aerosolization in a confined public space (e.g., restrooms or elevators).

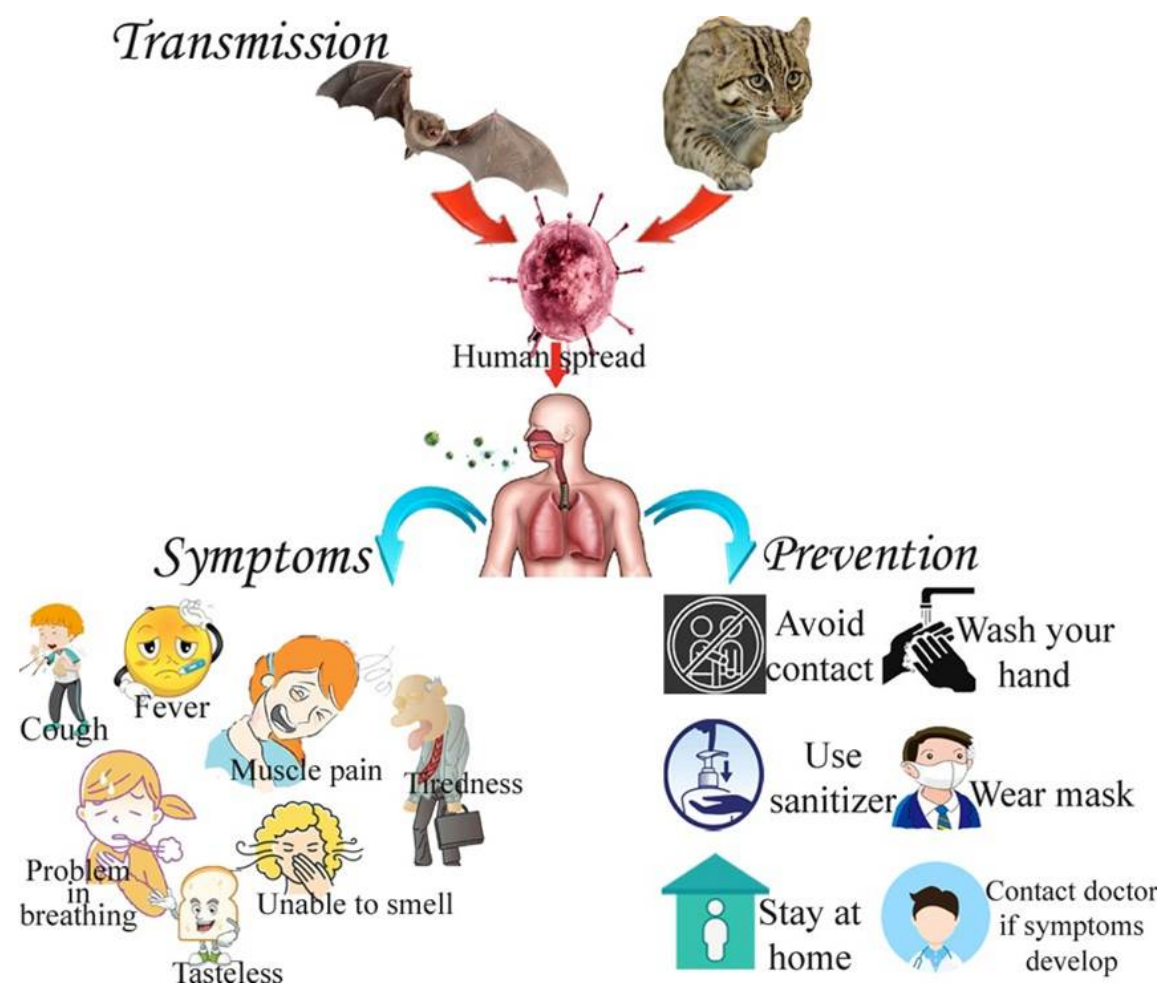

Figure 1: This is a caption

Figure: 2 Bats are the primary reservoir of an extensive variety of coronaviruses, including severe acute 
respiratory syndrome coronavirus (SARS-CoV) -like viruses. While, origin of SARS-CoV-2 is suspected from bats and unknown intermediate hosts via crossing the species barrier and jump into humans. The time where no countermeasure or vaccine is available, Virus-host interaction may be inhibited by applying the preventive measures.

\subsection{Clinical Manifestations}

COVID19 typically begins with the abrupt onset of symptoms following an incubation period thought to be within 14 days post exposure, with most cases occurs approximately four to five days after exposure ${ }^{41}$. Guan 2019 reported that patients with confirmed symptomatic COVID-19 have median incubation period is four days ${ }^{42}$. COVID19 can infect the patients of any age group, although adults of middle age and older are most commonly affected ${ }^{43}$. Recent study suggested that older age people are more prone to COVID19 infection and associated with high mortality, with a case $8 \%$ fatality rate in 70 to 79 year old and $15 \%$ in above 80 years old patients. In United States, 2449 patients diagnosed with COVID-19 between February 12 and March 16, 2020 and hospitalized in intensive care unit (ICU) in which; $67 \%$ of cases was diagnosed with the age of [?] 45 years. ${ }^{44}$ The infection rate is similar to the findings reported in China, whereas, mortality was highest among older individuals, with 80 percent of deaths occurred in the aged of [?]65 years. The symptomatic infection of COVID-19 is primarily characterized by fever, cough, dyspnea, and bilateral infiltrates on chest imaging consist of pneumonia like serious manifestation ${ }^{6}$. However, symptomatic presentation and clinical features of COVID-19 are very common and difficult to distinguish between other viral respiratory illness. High grade fever, chest discomfort and breathing issue determine the severity of the disease ${ }^{42,45,46}$. Other minor and common symptoms have been reported like headache, sore throat, and rhinorrhea. Apart from respiratory symptoms, gastrointestinal symptoms include, nausea and diarrhea have also been reported in some patients, but these are relatively uncommon ${ }^{42,46,47}$. On 23 march 2020, The American Academy of Otolaryngology stated about more specific symptoms of COVID-19 infection in patients that loses the sense of smell and taste are very rare and specific which not reported in other viral respiratory illness.. Therefore, clinicians advised patients to isolate themselves if they have symptoms like loss of smell and taste as these could be the key symptoms of COVID-19.

\subsection{Acute respiratory distress syndrome}

Acute respiratory distress syndrome (ARDS) indicates new-onset of respiratory failure. It is a major complication in patients with severe disease. ARDS is distinguished on the basis varying degrees of hypoxia based on values of $\mathrm{PaO} 2 / \mathrm{FiO}^{23}$. A study includes single-center case series of 138 hospitalized patients with confirmed NCIP in Wuhan, published by Wang in March 2020, reported that, ARDS was developed in 20 percent after a median of eight days, and mechanical ventilation was implemented in 12.3 percent of affected patients ${ }^{48}$. In another study of 201 hospitalized patients ([?]65 yrs. age) with COVID-19 in Wuhan, 41 percent developed ARDS and diabetes mellitus, hypertension was associated with ARDS $^{49}$. Other complications have included arrhythmias, acute cardiac injury, and multiple organ failure. According to the WHO, recovery time appears to be around two weeks for mild infections and three to six weeks for severe disease ${ }^{50}$. ARDS in severe and complicated cases can be monitored and confirmed by the chest imagining by computed tomography scan (CT scan), chest X-ray and lungs Ultrasound for the better diagnosis in critical cases. Chest CT scan in patients with COVID-19 commonly demonstrates ground-glass opacification with or without consolidative abnormalities, consistent with viral pneumonia ${ }^{51,52}$. Apart from radio findings, COVID-19 positive patients' blood analysis reveals the white blood cell count can vary. Leukopenia, leukocytosis, and lymphopenia have been reported, from which lymphopenia appears most commonly. Elevated lactate dehydrogenase (LDH) and serum ferritin level was common. While elevated aminotransferase and D-dimer levels, have also been observed along with more severe lymphopenia associated with mortality. On admission, many patients with pneumonia have normal serum procalcitonin levels; however, It is more likely to be elevated in patients those requiring ICU care $^{45,46,48}$.

\subsection{Diagnosis:}

To diagnose the COVID-19 pandemic, epidemiological factors are used to assess the requirement of testing. 
These include close contact with a laboratory-confirmed patient within 14 days of symptoms or travel history to an infected area within 14 days of symptom onset, common set of clinical symptoms like fever, cough and myalgia or fatigue etc. Viral pneumonia can be correctly diagnosed by preliminary chest CT scan. It had a low rate of missed diagnosis of COVID-19 $(3.9 \%, 2 / 51)^{53}$ and may be useful as a standard method for the rapid diagnosis of COVID-19 to optimize the management of patients. However, these factors are only helpful to segregate the suspected persons to avoid community spread and not enough to identify the COVID19 patients from the other viral respiratory illness. Hence, the quick, specific and mass testing is one of the most important ways to understand and stop the spread of COVID-19. It may allow us in understanding the spread of the disease, devising evidence-based measures to slow down the spread and infected people to know that they are infected. This can help them to receive the needed care as well as take measures to reduce the probability of infecting others ${ }^{21}$.

Clinical manifestations are not enough to identify the COVID19 patients from the other viral respiratory illness therefore there is strong need for laboratory tests. Patients having above symptomatology or suspected cases, as discussed above, should undergo testing for SARS-CoV-2. CDC recommends the most appropriate sample is nasopharyngeal swab specimen to test for SARS-CoV-2 ${ }^{54}$. An oropharyngeal swab can be collected but is not essential; if collected, it should be placed in the same container as the nasopharyngeal specimen. Sputum should only be collected from patients with productive cough; induction of sputum is not indicated. Presently SARS-CoV-2 RNA detection is possible by reverse-transcription polymerase chain reaction (RTPCR). A positive test for SARS-CoV-2 confirms the diagnosis of COVID-19. If first test sample gives negative result and suspicion for COVID-19 remains, few days later resampling and testing from multiple respiratory tract sites should be performed ${ }^{55,56}$. When COVID-19 is suspected, infection control measures should be implemented and public health officials notified. Patients who do not need urgent care should be encouraged to call prior to presenting to a health care facility for evaluation. In countries including India, several helpline numbers have been introduced where patient can get information and educated regarding the need for testing over the phone. Such strategy might be helpful to reduce the exposure of other during travelling to labs and health setups as well as lower the burden of COVID-19 threat. Unfortunately in many countries around the world, the capacity for COVID-19 testing is still low and became a reason for not have a good understanding of the spread of this pandemic disease ${ }^{57}$. Taking this as serious global disaster, several assays (in house and commercially) have been practiced at different nations which may detect only the novel virus and some may also detect other strains (e.g. SARS-CoV) that are genetically similar. WHO has also listed few of them on their website who shared their protocols with willing to send reagents or reagent mixes prepared in their laboratories, with or without associated fees ${ }^{21}$. The U.S. Food and Drug Administration (FDA) is moving much more quickly to grant special 'emergency use authorization' to equipment and tests that could help increase testing for the novel coronavirus in the United States.

\subsection{Rapid Diagnosis Tests for COVID19:}

Recently, Cepheid has developed a rapid molecular test which can detect the COVID19 after the 45 minutes of procedure. It's also a PCR-based test, with high rates of accuracy just like the lab-based testing. Cepheid an American molecular diagnostics company, Danaher Corporation, Sunnyvale, California, United States started to facilitate this rapid test method in the United States after the approval of US FDA. Development and validation of serological tests for antigen or antibody detection test system for COVID-19 may be key milestone in future. Diagnostic tools like Cepheid's, Scanwell's forthcoming test (looks for antibodies in a person's blood), as well as other potential alternative test methods than can be done entirely at home are much-needed in the strategy of coronavirus mitigation

\subsection{Available Preventive Therapy:}

At present, there is no specific cure or preventive therapeutics available against COVID-19. Certain investigational agents have been described in observational series or are being used anecdotally based on invitro or extrapolated evidence. However, no specific drug is approved for the treatment of COVID-19 by US Food and Drug Administration (FDA). In present, clinical management includes infection prevention and control measures and supportive care, including supplementary oxygen and mechanical ventilator support 
is adopted only way of protection from the COVID19. Arrays of drugs approved for other indications as well as several investigational drugs are being studied in hundreds of clinical trials that are underway across the globe. CDC releases a document for the purpose to provide information on two of the approved drugs (chloroquine and hydroxychloroquine) in which one of the investigational agents (remdesivir) is currently used in the United States and other countries. Therefore, it is important to acknowledge that there are no controlled supporting data is available for the use of any of these agents, and their efficacy for COVID19 is unknown. A study in China reported that chloroquine treatment of COVID-19 patients had clinical and virologic benefit versus a comparison group, and chloroquine was added as a recommended antiviral for treatment of COVID-19 in China ${ }^{58}$. Based upon limited in-vitro and anecdotal data, chloroquine or hydroxychloroquine are currently recommended for treatment of hospitalized COVID-19 patients in several countries. Antiviral drug Remdesivir is an investigational intravenous drug that inhibits viral replication through premature termination of RNA transcription and has in-vitro activity against SARS-CoV-2 and both in-vitro and in-vivo activity against related beta coronaviruses ${ }^{59,60,61}$. Other antiviral drugs which are used in management of HIV infection such as Lopinavir-and Ritonavir did not show promise effect against the hospitalized COVID-19 patients with pneumonia reported in a recent clinical trial at China ${ }^{62}$. In India, clinicians of SMS medical college have treated successfully 4 Italian patients with lopinavir-ritonavir and hydroxychloroquine combinations. As scientists' race to find a cure and vaccine, China is increasingly turning to its traditional remedies. As of late last month, more than $85 \%$ of all coronavirus patients in China about 60,000 people had received herbal remedies alongside mainstream antiviral drugs, according to the Ministry of Science and Technology China. Jun-ling Ren, 2020 published research study; Traditional Chinese Medicine (TCM) for COVID-19 treatment can inhibit the replication of COVID-19 by acting on multiple ribosomal proteins and lead to strong immune response and inflammatory storm ${ }^{63}$. TCM has been promoted as a general prescription in the diagnosis and treatment plan of COVID-19 in China ${ }^{38}$. Similarly, in India Ministry of AYUSH has issued advisory to use the Ayurveda, Siddha, Unani and Homeopathy as preventive measures. Historical background of these medicines is also supporting the use of this system of medicine as preventive measures. However there is no controlled supporting data available for the use of any of these traditional medicines, and their efficacy for COVID-19 is unknown. Hence, the research scope of these medicines with valid scientific evidences is much worthy to combat the pandemic of COVID-19.

\subsection{Prevention:}

In the meantime, personnel protective measures, health hygiene, self- isolation/quarantine of suspected person and screening of infected patient with proper isolation are the only ways of prevention to rapid spread of COVID19. Simultaneously, community awareness can be most useful, like patients and civilian must cover mouth during coughing and sneezes and wear the mask which may help to prevent aerosol transmission. Frequent hand washing with soap and water is also required prior to entry into a health care facility. Person should not touch promptly to handrails, lifts and stairs. Separate waiting areas for patients with respiratory symptoms should be designated, if possible. Otherwise, at least six feet distance should be there form the regular waiting areas in a hospital to avoid the exposure of others. Suspected patients should use the hand sanitizer and avoid touching the mouth, eyes and nose. CDC recommends that standard, contact, and droplet precautions in addition to eye protection be used for any patient with an undiagnosed respiratory infection or who is not under consideration for COVID-19. This may help to reduce the risk of spread from unsuspected COVID-19 cases. To avoid the community transmission, the traveling should be postponed and no handshaking may be useful strategies ${ }^{64}$. WHO also recommends standard, contact, and droplet precautions, with eye or face protection, addition of airborne respirator (N95 respirator) is must during aerosol-generating procedures ${ }^{65}$. Indian government has been strictly adhered with such strategies therefore the transmission rate of COVID19 is very less as compare to other developed country in third week of first positive case. A report of 138 patients with covid19 in china was estimated that $43 \%$ acquired infection in the hospital ${ }^{48}$. Healthcare workers have potential risk of exposure to COVID-19. Therefore, CDC has provided guidelines for work restriction, monitoring for it's strictly adherence. A study suggested that, viral RNA can be detected on nearly all surfaces tested (handles, light switches, bed and handrails, interior doors and windows, toilet bowl, sink basin) in the airborne infection isolation room of a patient with 
symptomatic mild COVID-19 prior to routine cleaning. Thus, such study extends the knowledge of viral transmission and survival of COVID19 through plastic and metal surfaces might be possible that enhance the risk of environmental exposure and transmission ${ }^{66,67}$. Therefore, environmental infection control procedures should also be implemented to reduce the spread of COVID-19 virus ${ }^{33,54,56,64}$.

\subsection{Need of Vaccination:}

At present scenario, there is urgent requirement of vaccine to prevent COVID-19 outbreak. Entire world has joined hands and working in the development of cure and preventive measure for COVID19 in the form of drug or vaccine, respectively. Several vaccines are in the phase of clinical trial and may became game changer in fight of COVID19, if get success in near future.

\subsection{Conclusion:}

COVID-19 pandemic imposes a heavy socioeconomic burden on all societies. Hospital admission, treatment and ICU are more often necessary in high-risk individuals such as the elder age people, pregnant ladies and children all around the globe. However, the impact of COVID-19 cannot be neglected even in young adults. COVID-19 is highly contagious in nature which makes them more lethal and threat for public health. The rapid spread of disease requires intense surveillance and isolation protocols to prevent further community transmission. Current treatment strategies are based upon anecdotal data, chloroquine or hydroxychloroquine. Moreover, antiviral drug remdesivir along with oxygen therapy is currently recommended for treatment of hospitalized COVID-19 patients in several countries. No specific medication or vaccine has been developed so far. Hence, a new and specific antiviral chemoprophylaxis is required that may be helpful to reduce the morbidity and mortality allied to COVID-19. Apart it, prophylactic vaccination is intense need for the future prevention of SARS-COV2 related pandemic.

\subsection{Reference:}

1. Parvez MK, Parveen S. Evolution and Emergence of Pathogenic Viruses: Past, Present, and Future. Intervirology 2017; 60: 1-7

2. Hui DS, Azhar E, Madani TA, Ntoumi F, Kock R, Dar O, Ippolito G, Mchugh TD, Memish ZA, Drosten C, Zumla A, Petersen E. The continuing 2019-nCoV epidemic threat of novel coronaviruses to global health - The latest 2019 novel coronavirus outbreak in Wuhan, China. Int J Infect Dis 2020; 91: 264-266.

3. Hui DSC, Zumla A. Severe acute respiratory syndrome: historical, epidemiologic, and clinical features. Infect Dis Clin North Am 2019; 33: 869-889.

4. Azhar EI, Hui DSC, Memish ZA, Drosten C, Zumla A. The Middle East Respiratory Syndrome (MERS). Infect Dis Clin North Am 2019; 33: 891-905.

5. Coronavirus disease (COVID-2019) situation reports. Geneva: World Health Organization, 2020. (https://www. who.int/emergencies/diseases/novel-coronavirus-2019/situation-reports/).

6. Marco C, Michael R, Arturo C, Scott CD, Raffaela DN.Features, Evaluation and Treatment Coronavirus (COVID-19). In: Stat Pearls. Treasure Island (FL): Stat Pearls Publishing 2020.

7. Perlman S, Netland J. Coronaviruses post-SARS: update on replication and pathogenesis. Nat Rev Microbiol 2009; 7: 439-450.

8. Coronavirus Disease 2019 (COVID-19) Symptoms. Centers for Disease Control and Prevention. United States. 10 February 2020.

9. Q\&A on coronaviruses (COVID-19). World Health Organization (WHO). Retrieved 11 March 2020.

10. Zhu N, Zhang D, Wang W, Li X, Yang B, Song J, Zhao X, Huang B, Shi W, Lu R, Niu P, Zhan F. A novel coronavirus from patients with pneumonia in China. N Engl J Med 2020; 382: 727-733. 
11. Chan JF, Kok KH, Zhu Z, Chu H, To KK, Yuan S, Yuen KY. Genomic characterization of the 2019 novel human-pathogenic coronavirus isolated from a patient with atypical pneumonia after visiting Wuhan. Emerg Microbes Infect 2020; 9: 221-236.

12. Ren LL, Wang YM, Wu ZQ, Xiang ZC, Guo L, Xu T, Jiang YZ, Xiong Y, Li YJ, Li XW, Li H, Fan GH, Gu XY, Xiao Y, Gao H, Xu JY, Yang F, Wang XM, Wu C, Chen L, Liu YW, Liu B, Yang J, Wang XR, Dong J, Li L, Huang CL, Zhao JP, Hu Y, Cheng ZS, Liu LL, Qian ZH, Qin C, Jin Q, Cao B, Wang JW. Identification of a novel bat-origin coronavirus causing severe pneumonia in human: a descriptive study. Chin Med J 2020. [Epub ahead of print] doi: 10.3760/cma.j.issn.0366-6999.2020.00.E001

13. Roujian Lu, Zhao X, Li J, Niu P, Yang B, Wu H, Wang W, Song H, Huang B, Zhu N, Bi Y, Ma X, Zhan F, Wang L, Hu T, Zhou H, Hu Z, Zhou W, Zhao L, Chen J, Meng Y, Wang J, Lin Y, Yuan J, Xie Z, Ma J, Liu WJ, Wang D, Xu W, Holmes EC, Gao GF, Wu G, Chen W, Shi W, Tan W. Genomic characterisation and epidemiology of 2019 novel coronavirus: implications for virus origins and receptor binding. Lancet 2020; 395: 565-574.

14. Zhou P, Yang XL, Wang XG, Hu B, Zhang L, Zhang W, Si HR, Zhu Y, Li B, Huang CL, Chen HD, Chen J, Luo Y, Guo H, Jiang RD, Liu MQ, Chen Y, Shen XR, Wang X, Zheng XS, Zhao K, Chen QJ, Deng F, Liu LL, Yan B, Zhan FX, Wang YY, Xiao GF, Shi ZL. A pneumonia outbreak associated with a new coronavirus of probable bat origin. Nature 2020; 579: 270-273.

15. Letko M, Marzi A, Munster V. Functional assessment of cell entry and receptor usage for SARS-CoV-2 and other lineage B betacoronaviruses. Nat Microbiol 2020; 5: 1-8.

16. Yan B, Lingsheng Y, Wei T, Tian F, Jin DY, Chen L, Wang M. Presumed Asymptomatic Carrier Transmission of COVID-19. JAMA 2020. [Epub ahead of print] doi: 10.1001/jama.2020.2565.

17. Coronavirus incubation could be as long as 27 days, Chinese provincial government says - Reuters, Feb. $22,2020$.

18. Hui DS, Azhar E, Madani TA, Ntoumi F, Kock R, Dar O, Ippolito G, Mchugh TD, Memish ZA, Drosten C, Zumla A, Petersen E. The continuing 2019-nCoV epidemic threat of novel coronaviruses to global health - The latest 2019 novel coronavirus outbreak in Wuhan, China. Int J Infect Dis 2020; 91: 264-266

19. WHO Afghanistan daily brief COVID-19 No.19 (25 March 2020). https://www . humanitarianresponse . info/sites/www.humanitarianresponse.info/files/documents/files/daily_brief_covid-19_25_march_ 2020.pdf

20. CT provides best diagnosis for COVID-19. Science Daily. 26 February 2020. Retrieved 2 March 2020.

21. Report of the WHO-China Joint Mission on Coronavirus Disease 2019 (COVID-19). 16-24 Feb 2020. https://www. who. int/docs/default-source/coronaviruse/who-china-joint-mission-on-covid-19final-report.pdf

22. https://www . aljazeera.com/news/2020/03/italy-bans-internal-travel-stop-virus-spreadlive-updates-200322235532945.html

23. Cascella M, Rajnik M, Cuomo A, Dulebohn SC, Napoli RD: Features, Evaluation and Treatment Coronavirus (COVID-19). Stat Pearls Publishing, Treasure Island, FL; 2020.

24. Zhu N, Zhang D, Wang W, Li X, Yang B, Song J, Zhao X, Huang B, Shi W, Lu R, Niu P, Zhan F, Ma X, Wang D, Xu W, Wu G, Gao GF, Tan W. A novel coronavirus from patients with pneumonia in China, 2019. N Engl J Med 2020; 382: 727-733.

25. Yin Y, Wunderink RG. MERS, SARS and other coronaviruses as causes of pneumonia. Respirology 2018; 23: 130-137.

26. Zhou P, Yang XL, Wang XG, Hu B, Zhang L, Zhang W, Si HR, Zhu Y, Li B, Huang CL, Chen HD, Chen J, Luo Y, Guo H, Jiang RD, Liu MQ, Chen Y, Shen XR, Wang X, Zheng XS, Zhao K, Chen QJ, Deng 
F, Liu LL, Yan B, Zhan FX, Wang YY, Xiao GF, Shi ZL. A pneumonia outbreak associated with a new coronavirus of probable bat origin. Nature 2020; 579: 270-273.

27. Giovanetti M, Benvenuto D, Angeletti S, Ciccozzi M. The first two cases of 2019-nCoV in Italy: where they come from?. J Med Virol 2020; 92: 518-521.

28. Paraskevis D, Kostaki EG, Magiorkinis G, Panayiotakopoulos G, Sourvinos G, Tsiodras S. Full-genome evolutionary analysis of the novel corona virus $(2019-\mathrm{nCoV})$ rejects the hypothesis of emergence as a result of a recent recombination event. Infect Genet Evol 2020; 79: 104-212.

29. Rolling updates on coronavirus disease (COVID-19)- WHO, 26 March 2020. https://www.who.int/ emergencies/diseases/novel-coronavirus-2019/events-as-they-happen

30. Rothe C, Schunk M, Sothmann P, Bretzel G, Froeschl G, Wallrauch C. Transmission of 2019-nCoV Infection from an Asymptomatic Contact in Germany. N Engl J Med 2020; 382: 970-971.

31. Ecuador confirms five new cases of coronavirus, all close to initial patient. Reuters. 2 March 2020. Archived on 2 March 2020. Retrieved 5 March 2020.

32. Wee SL, McNeil Jr. DG, Hernández JC. W.H.O. Declares Global Emergency as Wuhan Coronavirus Spreads. The New York Times. 2020 Archived on 30 January 2020. Retrieved 30 January 2020.

33. WHO Director-General's opening remarks at the media briefing on COVID-19 - 11 March 2020. World Health Organization (WHO) (Press release). 11 March 2020. Archived from the original on 11 March 2020. Retrieved 12 March 2020.

34. Jing Lu, Liu Zhe, Jiufeng Sun, Huifang Lin, Jingju Peng, Qianlin Xiong. Genomic epidemiology of hCoV-19 in Guangdong Province, China Novel 2019 coronavirus (Guangdong Provincial Institution of Public Health, Guangzhou, China).

35. Centers for Disease Control and Prevention. Severe outcomes among patients with Coronavirus Disease 2019 (COVID-19)- United States, February 12-March 16, 2020. https://www.cdc.gov/mmwr/volumes/69/wr/mm6912e2. (Accessed on March 19, 2020)

36. Yan B, Lingsheng Y, Wei T, Tian F, Jin DY, Chen L, Wang M Presumed asymptomatic carrier transmission of COVID-19. JAMA 2020; Epub ahead of print.

37. Cai J, Sun W, Huang J, Gamber M, Wu J, He G. Indirect virus transmission in cluster of COVID-19 cases, Wenzhou, China, 2020. Emerg Infect Dis 2020; 26. [Epub ahead of print] doi: 10.3201/eid2606.200412.

38. National Health Commission of the People's Republic of China. Guideline on diagnosis and treatment of COVID19 (Trial $6^{\text {th }}$ edition).

39. Centers for Disease Control and Prevention. Interim Guidelines for Collecting, Handling, and Testing Clinical Specimens from Persons Under Investigation (PUIs) for Coronavirus Disease 2019 (COVID-19). February 14, 2020. https://www.cdc.gov/coronavirus/2019-nCoV/lab/guidelines-clinical-specimens.html (Accessed on March 15, 2020).

40. National Academies Press. Rapid expert consultation on the possibility of bioaerosol spread of SARSCoV-2 for the COVID-19 pandemic. April 1, 2020. doi: 10.17226/25769.

41. Li Q, Guan X, Wu P, Wang X, Zhou MPH, Tong L, Ren R, Leung KSM, Lau EHY, Wong JY, Xing X, Xiang N, Wu Y, Li C, Chen MPHQ, Li D, Liu MPHT, Zhao J, Liu M, Tu W, Chen C, Jin L, Yang R, Wang Q, Zhou MPSH, Wang R, Liu H, Luo L, Liu Y, Shao G, Li H, Tao MPHZ, Yang MPHY, Deng Z, Liu B, Ma MPHZ, Zhang Y, Shi G, Lam MPHTT, Wu JT, Gao GF, Cowling BJ, Yang B, Leung GM, Feng Z. Early Transmission Dynamics in Wuhan, China, of Novel Coronavirus-Infected Pneumonia. N Engl J Med. 2020; 382: 1199-1207. 
42. Guan W, Ni Z, Hu Y, Liang W, Ou C, He J, Liu L, Shan H, Lei C, Hui DSC, Du B, Li L, Zeng G, Yuen KY, Chen R, Tang C, Wang T, Chen P, Xiang J, Li S, Wang JL, Liang Z, Peng Y, Wei L, Liu Y, Hu YH, Peng P, Wang JM, Liu J, Chen Z, Li G, Zheng Z, Qiu S, Luo J, Ye C, Zhu S, Zhong Z . Clinical Characteristics of Coronavirus Disease 2019 in China. N Engl J Med. 2020; [Epub ahead of print] doi: 10.1056/NEJMoa2002032.

43. World Health Organization. Infection prevention and control during health care when novel coronavirus (nCoV) infection is suspected. January 25, 2020. https://www.who.int/publications-detail/infectionprevention-and-control-during-health-care-when-novel-coronavirus-(ncov)-infection-is-suspected-20200125 (Accessed on February 04, 2020).

44. Centers for Disease Control and Prevention. Interim guidance for persons who may have 2019 Novel Coronavirus (2019-nCoV) to prevent spread in homes and residential communities. https://www.cdc.gov/coronavirus/2019ncov/hcp/guidance-prevent-spread.html\#First_heading (Accessed on February 06, 2020).

45. Chen N, Zhou M, Dong X, Qu J, Gong F, Han Y, Qiu Y, Wang J, Liu Y, Wei Y, Xia J, Yu T, Zhang X, Zhang L. Epidemiological and clinical characteristics of 99 cases of 2019 novel coronavirus pneumonia in Wuhan, China: a descriptive study. Lancet 2020; 395: 507-13.

46. Huang C, Wang Y, Li X, Ren L, Zhao J, Hu Y, Zhang L, Fan G, Xu J, Gu X, Cheng Z, Yu T, Xia J, Wei Y, Wu W, Xie X, Yin W, Li H, Liu M, Xiao Y, Gao H, Guo L, Xie J, Wang G, Jiang R, Gao Z, Jin Q, Wang J, Cao B. Clinical features of patients infected with 2019 novel coronavirus in Wuhan, China. Lancet 2020; 395: 497-506.

47. Wang V. Most Coronavirus Cases Are Mild. That's Good and Bad News. The New York Times 2020.

48. Wang D, Hu B, Hu C, Zhu F, Liu X, Zhang J, Wang B, Xiang H, Cheng Z, Xiong Y, Zhao Y, Li Y, Wang X, Peng Z. Clinical Characteristics of 138 Hospitalized Patients With 2019 Novel Coronavirus-Infected Pneumonia in Wuhan, China. JAMA 2020. [Epub ahead of print] doi: 10.1001/jama.2020.1585.

49. Wu C, Chen X, Cai Y, Xia J, Zhou X, Xu S, Huang H, Zhang L, Zhou X, Du C, Zhang Y, Song J, Wang S, Chao Y, Yang Z, Xu J, Zhou X, Chen D, Xiong W, Xu L, Zhou F, Jiang J, Bai C, Zheng J, Song Y. Risk Factors Associated with Acute Respiratory Distress Syndrome and Death in Patients with Coronavirus Disease 2019 Pneumonia in Wuhan, China. JAMA Intern Med 2020. [Epub ahead of print] doi: 10.1001/jamainternmed.2020.0994.

50. World Health Organization. Coronavirus disease (COVID-19) technical guidance: Surveillance and case definitions. https://www.who.int/emergencies/diseases/novel-coronavirus-2019/technical-guidance/surveillanceand-case-definitions (Accessed on February 28, 2020)

51. Shi H, Han X, Jiang N, Cao Y, Alwalid O, Gu J, Fan Y, Zheng C. Radiological findings from 81 patients with COVID-19 pneumonia in Wuhan, China: a descriptive study. Lancet Infect Dis 2020; 20: 425-434.

52. Zhao W, Zhong Z, Xie X, Yu Q, Liu J. Relation Between Chest CT Findings and Clinical Conditions of Coronavirus Disease (COVID-19) Pneumonia: A Multicenter Study. AJR Am J Roentgenol 2020; 3: 1-6.

53. Li Z, Yi Y, Luo X, Xiong N, Liu Y, Li S, Sun R, Wang Y, Hu B, Chen W, Zhang Y, Wang J, Huang B, Lin Y, Yang J, Cai W, Wang X, Cheng J, Chen Z, Sun K, Pan W, Zhan Z, Chen L, Ye F. Development and Clinical Application of A Rapid IgM-IgG Combined Antibody Test for SARS-CoV-2 Infection Diagnosis. J Med Virol 2020. doi: 10.1002/jmv.25727. [Epub ahead of print]

54. Centers for Disease Control and Prevention. Strategies to Prevent the Spread of COVID-19 in Long-Term Care Facilities (LTCF). https://www.cdc.gov/coronavirus/2019-ncov/healthcare-facilities/prevent-spread-inlong-term-care-facilities.html (Accessed on March 08, 2020).

55. Patel A, Jernigan DB, 2019-nCoV CDC Response Team. Initial Public Health Response and Interim Clinical Guidance for the 2019 Novel Coronavirus Outbreak - United States, December 31, 2019-February 4, 2020. MMWR Morb Mortal Wkly Rep 2020; 69: 140-146. 
56. World Health Organization. Home care for patients with suspected novel coronavirus (nCoV) infection presenting with mild symptoms and management of contacts. Updated February 4, 2020. https://www.who.int/publicationsdetail/home-care-for-patients-with-suspected-novel-coronavirus-(ncov)-infection-presenting-with-mild-symptomsand-management-of-contacts (Accessed on February 14, 2020).

57. World Health Organization. Laboratory testing for 2019 novel coronavirus (2019-nCoV) in suspected human cases. Updated March 2, 2020 https://www.who.int/publications-detail/laboratory-testing-for-2019novel-coronavirus-in-suspected-human-cases20200117 (Accessed on March 15, 2020).

58. Gao J, Tian Z, Yang X. Breakthrough: Chloroquine phosphate has shown apparent efficacy in treatment of COVID-19 associated pneumonia in clinical studies. Biosci Trends 2020; 14: 72-73

59. Wang M, Cao R, Zhang L, Yang X, Liu J, Xu M, Shi Z, Hu Z, Zhong W, Xiao G. Remdesivir and chloroquine effectively inhibit the recently emerged novel coronavirus (2019-nCoV) in vitro. Cell Res 2020; 30: 269-271.

60. Sheahan TP, Sims AC, Graham RL, Menachery VD, Gralinski LE, Case JB, Leist SR, Pyrc K, Feng JY, Trantcheva I, Bannister R, Park Y, Babusis D, Clarke MO, Mackman RL, Spahn JE, Palmiotti CA, Siegel D, Ray AS, Cihlar T, Jordan R, Denison MR, Baric RS. Broad-spectrum antiviral GS-5734 inhibits both epidemic and zoonotic coronaviruses. Sci Transl Med 2017; 9. doi: 10.1126/scitranslmed.aal3653.

61. Sheahan TP, Sims AC, Leist SR, Schäfer A, Won J, Brown AJ, Montgomery SA, Hogg A, Babusis D, Clarke MO, Spahn JE, Bauer L, Sellers S, Porter D, Feng JY, Cihlar T, Jordan R, Denison MR, Baric RS. Comparative therapeutic efficacy of remdesivir and combination lopinavir, ritonavir, and interferon beta against MERS-CoV. Nat Commun 2020; 11: 222. doi: 10.1038/s41467-019-13940-6.

62. Cao B, Wang Y, Wen D, Liu W, Wang J, Fan G, Ruan L, Song B, Cai Y, Wei M, Li X, Xia J, Chen N, Xiang J, Yu T, Bai T, Xie X, Zhang L, Li C, Yuan Y, Chen H, Li H, Huang H, Tu S, Gong F, Liu Y, Wei Y, Dong C, Zhou F, Gu X, Xu J, Liu Z, Zhang Y, Li H, Shang L, Wang K, Li K, Zhou X, Dong X, Qu Z, Lu S, Hu X, Ruan S Luo S, Wu J, Peng L, Cheng F, Pan L, Zou J, Jia C, Wang J, Liu X, Wang S, Wu X, Ge Q, He J, Zhan H, Qiu F, Guo L, Huang C, Jaki T, Hayden FG, Horby PW, Zhang D, Wang C. A Trial of Lopinavir-Ritonavir in Adults Hospitalized with Severe Covid-19. N Engl J Med 2020. [Epub ahead of print] doi: 10.1056/NEJMoa2001282.

63. Xu Z, Shi L, Wang Y, Zhang J, Huang L, Zhang C, Liu S, Zhao P, Liu H, Zhu L, Tai Y, Bai C, Gao T, Song J, Xia P, Dong J, Zhao J, Wang FS. Pathological findings of COVID-19 associated with acute respiratory distress syndrome. Lancet Respir Med 2020. doi: 10.1016/S2213-2600(20)30076-X. [Epub ahead of print].

64. Centers for Disease Control and Prevention. Interim Infection Prevention and Control Recommendations for Patients with Confirmed 2019 Novel Coronavirus (2019-nCoV) or Patients Under Investigation for 2019nCoV in Healthcare Settings. February 3, 2020. https://www.cdc.gov/coronavirus/2019-nCoV/hcp/infectioncontrol.html (Accessed on March 11, 2020).

65. World Health Organization. Infection prevention and control during health care when novel coronavirus (nCoV) infection is suspected. January 25, 2020. https://www.who.int/publications-detail/infectionprevention-and-control-during-health-care-when-novel-coronavirus-(ncov)-infection-is-suspected-20200125 (Accessed on February 04, 2020).

66. Ong SWX, Tan YK, Chia PY, Lee TH, Ng OT, Wong MSY, Marimuthu K. Air, Surface Environmental, and Personal Protective Equipment Contamination by Severe Acute Respiratory Syndrome Coronavirus 2 (SARS-CoV-2) From a Symptomatic Patient. JAMA 2020. [Epub ahead of print] doi: 10.1001/jama.2020.3227.

67. Rabenau HF, Cinatl J, Morgenstern B, Bauer G, Preiser W, Doerr HW. Stability and inactivation of SARS coronavirus. Med Microbiol Immunol 2005; 194: 1-6. 
